\title{
Analisis Perbandingan Kinerja Routing OSPF Dan EIGRP
}

\author{
Yoldi Novendra ${ }^{1}$, Yudhi Arta $^{2}$, Apri Siswanto ${ }^{3}$ \\ 1,2,3Program Studi Teknik Informatika, Fakultas Teknik, Universitas Islam Riau \\ e-mail:, ${ }^{1}$ yoldinovendra@student.uir.ac.id ${ }_{2}^{2}$ yudhiarta@eng.uir.ac.id, \\ 3aprisiswanto@eng.uir.ac.id
}

\begin{abstract}
The world of technology is currently experiencing rapid development, especially on Internet technology. Internet technology is a technology that is currently widely used by humans to communicate and send various data in distant distances quickly. In the process of data transmission and communication on Internet technology cannot be separated from the path used, the shorter the path used the faster the data sent. The problem becomes a benchmark in making this thesis is to compare two pieces routing OSPF routing protocol and EIGRP has a function the same is to do the routing process which will be measured with QoS parameters such as throughput, delay and packet loss with the delivery load of audio and video as measured by wireshark application. The results show that OSPF routing protocol has lower throughput, delay and packet loss than EIGRP routing.
\end{abstract}

Keywords : Open Shortest Path First (OSPF), Enchanced Interior Gateway Routing Protocol (EIGRP), Quality of Service (Qos), Wireshark.

\begin{abstract}
Abstrak
Dunia teknologi saat ini mengalami perkembangan yang cepat, terlebih pada teknologi internet. Teknlogi internet merupakan sebuah teknologi yang saat ini banyak digunakan oleh manusia untuk berkomunikasi dan mengirim berbagai data dalam jarak yang saling berjauhan dengan cepat. Dalam proses pengiriman data dan komunikasi pada teknologi internet tidak terlepas dari jalur yang digunakan, semakin pendek jalur yang digunakan maka akan semakin cepat data yang dikirim, masalah yang menjadi tolak ukur dalam pembuatan skripsi ini adalah membandingkan 2 (dua) buah routing protokol routing OSPF dan EIGRP memiliki fungsi yang sama yakni melakukan proses routing dimana akan diukur dengan parameter $Q o S$ seperti troughput, delay dan paket loss dengan beban pengiriman berupa audio dan video yang diukur dengan aplikasi wireshark. Hasil menunjukkan bahwa routing protocol OSPF memiliki nilai troughput, delay dan paket loss lebih kecil dibandingkan routing EIGRP.
\end{abstract}

Kata kunci: Open Shortest Path First (OSPF), Enchanced Interior Gateway Routing Protocol (EIGRP), Quality of Service (QoS), Wireshark.

\section{PENDAHULUAN}

Teknologi internet pada decade terakhir ini mengalami peningkatan yang cukup siginifikan. Pada tahun 2018 ini diperkirakan jumlah pengguna internet mencapai 3, 8 Miliar. Teknologi internet merupakan sebuah teknologi yang saat ini banyak digunakan oleh manusia untuk berkomunikasi dan mengirim berbagai data dalam jarak yang saling berjauhan dengan cepat. Dalam proses pengiriman data dan komunikasi pada teknologi 
internet tidak terlepas dari jalur yang digunakan, semakin pendek jalur yang digunakan maka akan semakin cepat data yang dikirim, sehingga akan mudah terjadi komunikasi [1].

Ada beberapa jenis routing yang banyak digunakan namun, Routing protocol OSPF dan EIGRP merupakan routing protocol yang saat ini banyak diterapkan oleh para teknisi jaringan komputer pada jaringan komputer yang dibuat. $O S P F$ merupakan sebuah protokol routing yang dikembangkan untuk jaringan IP oleh Internet Engineering Task Force (IETF). Sesuai dengan namanya protokol ini memiliki dua karakteristik utama. Pertama protokol ini bersifat terbuka artinya spesifikasi dari protokol ini terbuka untuk umum dan yang kedua adalah routing dari $O S P F$ ini berbasis algoritma $S P F$, dan EIGRP merupakan routing protocol yang ditingkatkan (enhanced) dari pendahulunya yaitu IGRP dan hanya dapat digunakan oleh router yang diproduksi oleh Cisco, Inc. EIGRP menggunakan kosep autonomous system untuk menggambarkan router-router suatu jaringan yang beroperasi dengan protokol yang sama dan saling berbagi informasi routing yang sama [2].

Permasalahan yang ada pada routing OSPF dan EIGRP yaitu, routing OSPF tidak menghasilkan routing loop, mendukung penggunaan beberapa metrik sekaligus, serta membagi jaringan yang besar menjadi beberapa area, sedangkan routing EIGRP Melakukan konvergensi secara tepat ketika menghindari loop, memerlukan lebih sedikit memori dan proses. Oleh sebab itu pemilihan routing protocol yang tepat akan memperkuat manajemen lalu lintas data karena routing protocol tidak hanya didesain untuk mengubah ke jalur backup bila jalur utama tidak berhasil, routing protocol juga didesain untuk menentukan jalur mana yang terbaik untuk mencapai tujuan dan mengatasi situasi routing yang kompleks secara cepat dan akurat [3] .

\section{METODOLOGI PENELITIAN}

Dalam penelitian digunakan metode penelitian tindakan atau action research yang meliputi pengukuran parameter QoS yaitu Bandwidth, Delay dan Packet Loss pada topologi Jaringan yang di rancang [4]. Metode penelitian adalah cara dan langkah-langkah yang digunakan dalam melakukan penelitian. Pada penelitian dalam proses pengujian, cara dan langkah-langkah yang digunakan antara lain : Pengumpulan data, Konsep Teori, Perancangan topologi. Uraian metode penelitian yang digunakan dapat diuraikan sebagai berikut :

\subsection{Tinjauan Pustaka}

Penelitian yang dijadikan sebagai rujukan dalam penelitian ini antara lain : rujukan penelitian yang pertama adalah penelitian yang berjudul Analisis Kinerja Protokol Routing OSPF dan EIGRP Untuk Aplikasi Voip Pada Topologi Jaringan Mesh [5]. Mereka melakukan penelitian menguji bagaimana kinerja dari dua protokol routing, yaitu $O S P F$ dan EIGRP pada topologi jaringan mesh terhadap layanan VoIP. Pengujian routing $O S P F$ dan EIGRP dengan melakukan pengujian terhadap layanan VoIP.

Selanjutnya adalah penelitian yang berjudul Pengembangan Jaringan Komputer Universitas Surakarta Berdasarkan Perbandingan Protokol Routing Information Protokol (RIP) Dan Protokol Open Shortest Path First (OSPF) [6]. Mereka melakukan perancangan pengembangan jaringan komputer di Universitas Surakarta sehingga dapat mencukupi kebutuhan informasi dari pengguna dalam melakukan pertukaran data dengan melakukan perbandingan kemampuan protokol Routing Information Protokol (RIP) dengan protokol Open Shortest Path First (OSPF) kedalam desain pengembangan jaringan komputer. Serta menguji kemampuan dari protokol Routing Information Protokol (RIP) dan protokol Open 
Shortest Path First (OSPF) dalam menangani pertukaran data didalam sebuah jaringan komputer yang memiliki jumlah client yang banyak dan jaringan yang besar.

Rujukan penelitian yang selanjutnya adalah penelitian yang berjudul Analisis Unjuk Kerja RIPv2 Dan EIGRP Dalam Dynamic Routing Protocol [7]. Membandingkan kedua protokol tersebut dari aspek daftar tabel routing, informasi mengenai protokol routing, kemampuan menghasilkan tabel topologi, kemampuan mengenali router tetangga (tabel neighbor), melihat konektivitas jaringan, dan memeriksa jalur yang dilewati oleh paket data.

Sebagai tambahan rujukan adalah penelitian Musril, dkk [8] dengan judul "Analisis Unjuk Kerja RIPv2 Dan EIGRP Dalam Dynamic Routing Protocol". Beliau menarik kesimpulan yaitu EIGRP memiliki konvergensi yang lebih baik dibandingkan RIPv2. RIPv2 melakukan update tabel routing ke seluruh router, sedangkan EIGRP hanya pada router yang terkena dampak langsung dari perubahan topologi jaringan. EIGRP mampu menghasilkan tabel topologi dan tabel neighbor, sedangkan RIPv2 tidak.

\subsection{Pengumpulan Data}

Dalam melakukan proses pengujian, sangat diperlukan sebuah data yang benar, dan terbukti keakuratannya. Maka dari itu, untuk mendapatkan data yang benar dan akurat, teknik pengumpulan data dilakukan dengan cara sebagai berikut [14]:

a. Mengumpulkan Data

Proses pengumpulan data ini dilakukan dengan cara mengumpulkan data audio dan video dengan masing-masing lima buah format berbeda. Data yang diperoleh tersebut dilakukan pengujian dengan basis routing OSPF dan EIGRP menggunakan topologi star.

b. Penelitian Kepustakaan

Dalam melaksanakan penelitian kepustakaan, penulis melakukan pencarian bahan dengan membaca buku-buku, dokumen dan artikel yang berkaitan proses kerja dari routing $O S P F$ dan EIGRP.

\subsection{Konsep Teori}

Teori yang yang digunakan pada penelitian ini dapat diuraikan sebagai berikut :

\subsubsection{Routing $O S P F$}

Open Shortest Path First (OSPF) merupakan pengembangan dari routing protocol sebelumnya yaitu routing internet protocol (RIP) yang dibangun oleh Internet Enginering Task Force (IETF) pada tahun 1980 [9]. Routing OSPF menggunakan algoritma shorted path atau biasa disebut jalur terpendek dalam rangka membangun dan menghitung jalur terpendek ke semua jalur tujuan yang dikenal dengan istilah Algoritma Djikstra [10].

\subsubsection{Routing EIGRP}

Enhanced Interior Gateway Routing Protocol (EIGRP) adalah protocol dengan optimalisasi untuk meminimalkan ketidak stabilan routing yang terjadi setelah perubahan topologi, serta penggunaaan dan pengolahan daya bandwith pada router EIGRP menggunakan algoritma Difusssing Update Algorithm (DUAL) untuk mencari jalur terbaik [11] .

\subsubsection{Graphic Network Simulator (GNS3)}

GNS3 adalah sebuah program graphical network simulator yang dapat mensimulasikan topologi jaringan yang lebih kompleks dibandingkan dengan simulator lainnya. Program ini dapat dijalankan pada operating-systems, seperti Windows XP professional, windows 7, windows 8, windows 10 atau Linux Ubuntu [12]. 


\subsubsection{Quality of Service (QoS)}

Quality of Service adalah kemampuan sebuah jaringan untuk menyediakan layanan yang lebih baik lagi bagi layanan trafik yang melewatinya. $Q o S$ merupakan sebuah sistem arsitektur end to end dan bukan merupakan sebuah feature yang dimiliki oleh jaringan. Quality of Service suatu network merujuk ke tingkat kecepatan dan keandalan penyampaian berbagai jenis beban data di dalam suatu komunikasi. Aplikasi yang berbeda memerlukan suatu persyaratan QoS tertentu agar selama proses pentransmisian tidak terlalu banyak paket yang hilang, layanan real-time yang baik, delay yang rendah, dan alokasi bandwidth yang baik. Performansi kecepatan dan mengacu keandalan ke tingkat penyampaian berbagai jenis beban data di dalam suatu komunikasi yang meliputi troughput, delay dan paket loss [13].

\subsection{Perancangan Topologi Jaringan}

Analisa dilakakuan pada topologi yang sedang berjalan, dengan cara pengujian menggunakan aplikasi Wireshark. Selanjutnya, dilakukan pengembangan dan perancangan topologi baru yang akan dibangun berdasarkan analisa yang telah dilakukan sebelumnya. Dalam pengembangan sebuah proses routing terdiri dari beberapa tahapan. Adapun tahapan-tahapan tersebut dapat dilihat pada gambar 1 .

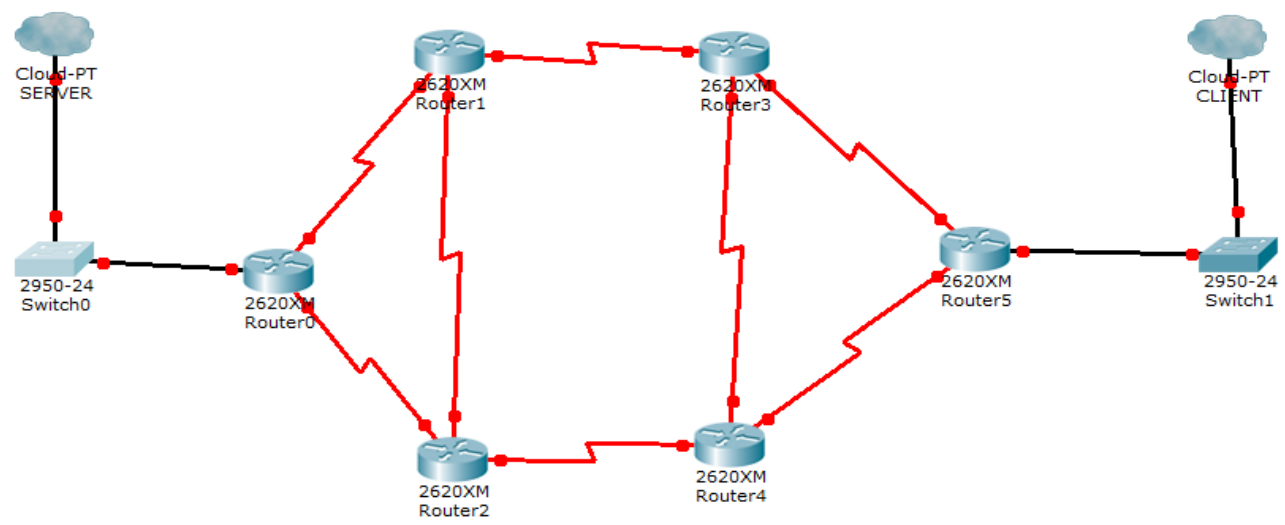

Gambar 1. Skema topologi jaringan STAR

Penjelasan skema proses desain jaringan topologi star dijabarkan sebagai berikut :

a. Cloud-PT Server

Cloud-pt server berfungsi sebagai penghubung antara komputer server dengan komputer client.

b. Router

Router adalah peralatan yang bekerja pada layer 3 Open System Interconnection (OSI). Router digunakan untuk menghubungkan host awal ke host tujuan.

c. Evaluasi

Pada tahapan ini, evaluasi dilakukan untuk mengetahui kinerja dari suatu desain jaringan. Berdasarkan desain jaringan menggunakan topologi star tersebut, maka untuk mengetahui kinerja dari topologi star yang digunakan, dengan melakukan pengujian pengiriman paket data berupa audio dan video. Dengan melakukan pengujian pengiriman paket data audio dan video dengan routing protocol $O S P F$ 
dan EIGRP, maka akan diketahui hasil troughput, delay dan paket loss. Jumlah data diketahui menggunakan aplikasi Wireshark untuk mendapatkan nilai Quality of Service $(Q o S)$, maka dapat diketahui nilai dari kedua perbandingan routing OSPF dan EIGRP.

\section{HASIL DAN PEMBAHASAN}

\subsection{Troughput Video}

Gambar 2 dibawah ini merupakan grafik perbandingan throughput pengujian video dengan dua buah routing dan penambahan satu buah routing yaitu routing RIP sebagai perbandingan routing OSPF dan EIGRP, skenario melakukan streaming di komputer klien kepada server. Pada troughput routing $O S P F$, nilai throughput lebih kecil dibanding troughput routing EIGRP dan RIP, hal ini disebabkan oleh kualitas video yang berbeda.

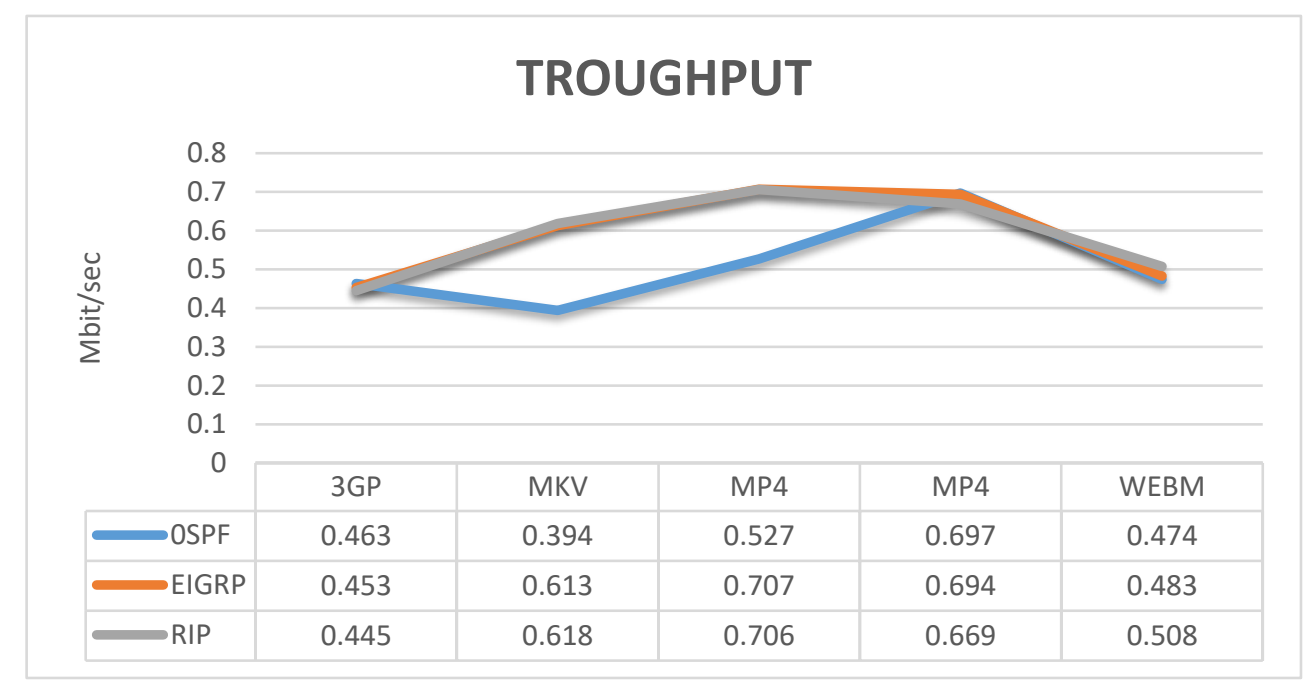

Gambar 2. Perbandingan Throughput routing OSPF, EIGRP dan RIP

\subsection{Delay Video}

Gambar 3 dibawah ini merupakan grafik perbandingan delay pengujian video dengan dua buah routing dan penambahan satu buah routing yaitu routing RIP sebagai perbandingan routing OSPF dan EIGRP, skenario melakukan streaming di komputer klien kepada server. Nilai routing OSPF medapatkan nilai delay yang paling kecil dan ikuti oleh routing RIP dan routing EIGRP pada hal ini disebabkan oleh sifat routing OSPF yang menggunakan algoritma djikstra yaitu pencarian rute terpendek untuk mencapai tujuan. 


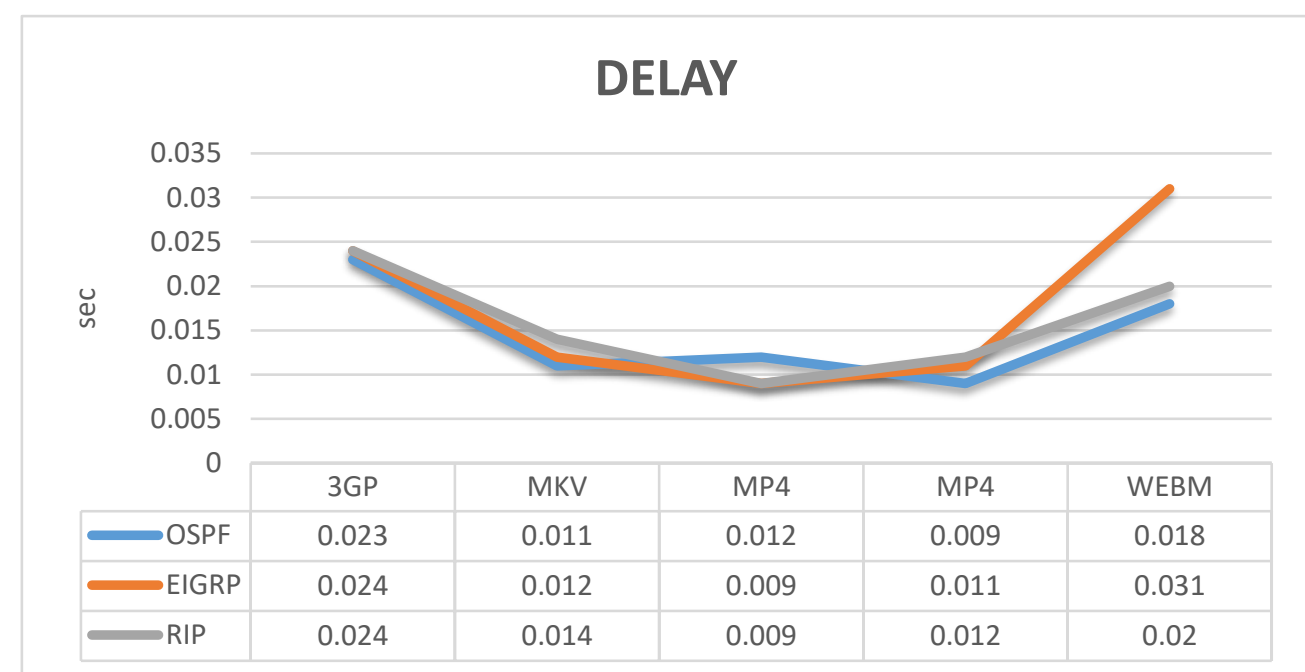

Gambar 3. Perbandingan Delay routing OSPF, EIGRP dan RIP

\subsection{Paket Loss Video}

Gambar 4 dibawah ini merupakan grafik perbandingan Paket Loss pengujian video dengan tiga buah routing yang berbeda skenario melakukan streaming di komputer server kepada komputer klien. Pada Paket Loss routing OSPF, nilai paket loss lebih besar disbanding nilai paket loss routing EIGRP dan RIP, jumlah lost packet routing RIP lebih rendah dibanding OSPF dan EIGRP. Hal ini disebabkan Semakin lama komunikasi terjadi jumlah lost packet juga semakin besar.

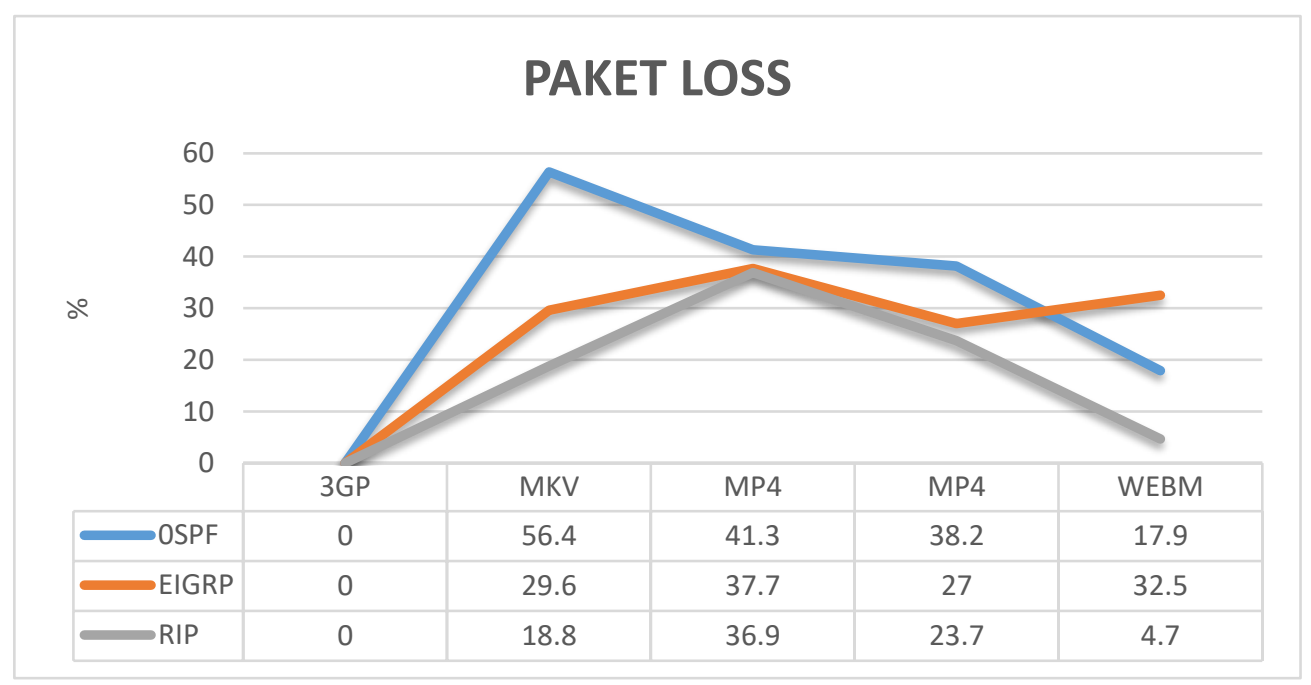

Gambar 4. Perbandingan Paket Loss Video routing OSPF, EIGRP dan RIP

\subsection{Troughput Audio}

Gambar 5 dibawah ini merupakan grafik perbandingan throughput pengujian audio dengan tiga buah routing yang berbeda skenario melakukan streaming di komputer server kepada klien. Pada troughput routing OSPF, EIGRP dan nilai throughput RIP memiliki troughput yang kecil dan nilai troughput yang sama. 


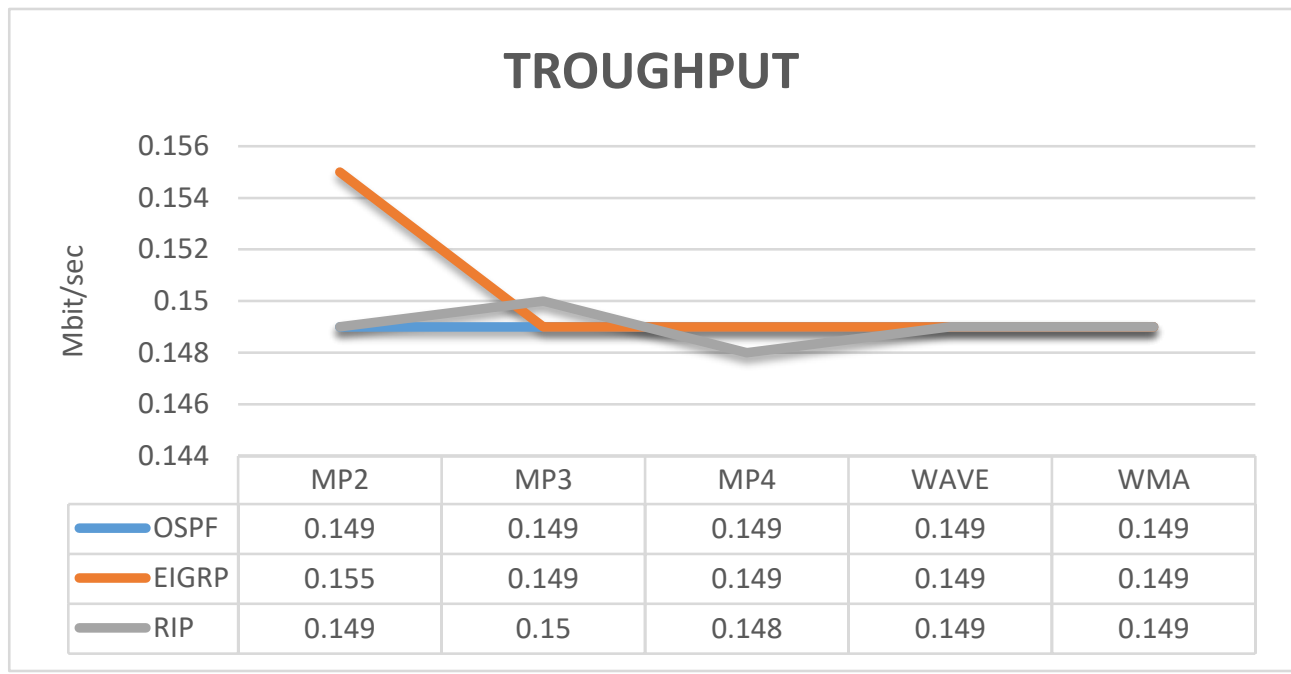

Gambar 5. Perbandingan Troughput Audio routing OSPF, EIGRP dan RIP

\subsection{Delay Audio}

Gambar 6 dibawah ini merupakan grafik perbandingan throughput pengujian audio dengan tiga buah routing yang berbeda skenario melakukan streaming di komputer server kepada klien. Nilai delay routing OSPF, EIGRP dan RIP mendapatkan nilai yang sama, hal ini disebabkan pengiriman paket data audio yang mempunyai ukuran file lebih kecil dibandingkan video.

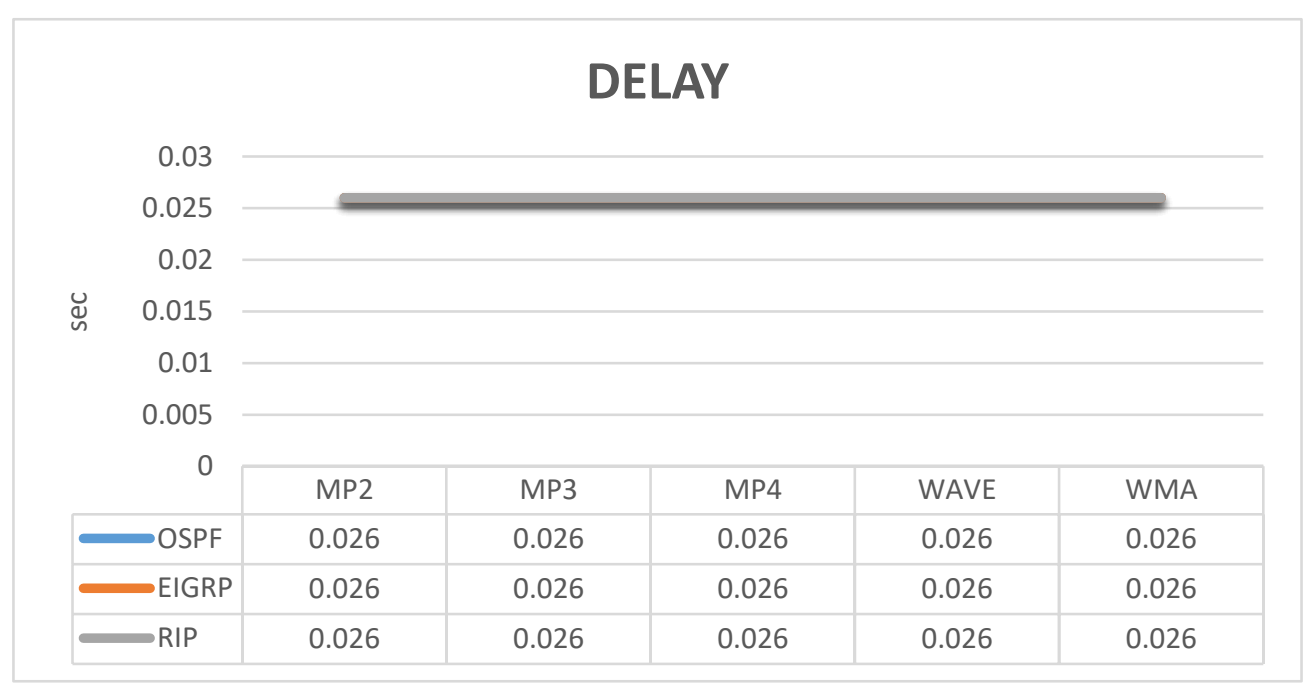

Gambar 6. Perbandingan Delay Audio routing OSPF, EIGRP dan RIP

\subsection{Paket Loss Audio}

Gambar 7 dibawah ini merupakan grafik perbandingan Paket Loss pengujian audio dengan tiga buah routing yang berbeda skenario melakukan streaming di computer server kepada klien. Mendapatkan nilai paket loss sebesar nol. Hal ini disebabkan selama menjalankan streaming audio tidak mengalami buffering. 


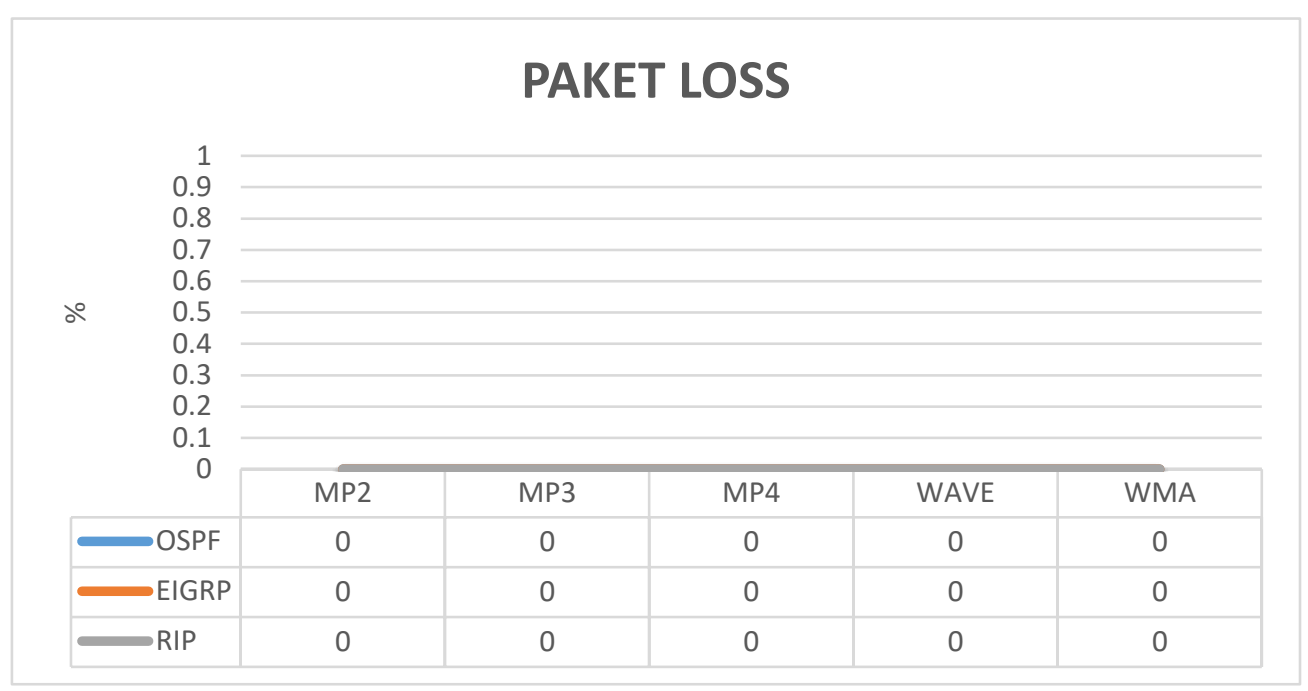

Gambar 7. Perbandingan Paket Loss Audio routing OSPF, EIGRP dan RIP

\subsection{Hasil tabel perbandingan Quality of Service (QoS)}

Pengujian routing dilakukan masing-masing sebanyak lima kali pengujian, data diuji dilakukan untuk mengetahui perbedaan Quality of Service $(Q o S)$ keakuratan hasil penilaian routing protocol yang paling baik. Pengujian ini dilakukan dengan menggunakan lima format video dan lima format audio data uji. Tabel hasil pengujian dapat dilihat pada tabel 1 .

Tabel 1. Hasil Pengujian Data Uji Audi dan Video

\begin{tabular}{|c|c|c|c|c|c|c|c|}
\hline Routing & & & 3gp & mkv & Mp4 & Mp4 & webm \\
\hline \multirow{7}{*}{ EIGRP } & \multirow{3}{*}{ VIDEO } & Troughput & 0,453 & 0,613 & 0,707 & 0,694 & 0,483 \\
\hline & & Delay & 0,024 & 0,012 & 0,009 & 0,011 & 0,031 \\
\hline & & Paket loss & $0,00 \%$ & $29,6 \%$ & $37,7 \%$ & $27,0 \%$ & $32,5 \%$ \\
\hline & & & Mp2 & Mp3 & Mp4 & wave & wma \\
\hline & \multirow{3}{*}{ AUDIO } & Troughput & 0,155 & 0,149 & 0,149 & 0,149 & 0,149 \\
\hline & & Delay & 0,026 & 0,026 & 0,026 & 0,026 & 0,026 \\
\hline & & Paket loss & $0,00 \%$ & $0,00 \%$ & $0,00 \%$ & $0,00 \%$ & $0,00 \%$ \\
\hline \multirow{8}{*}{ OSPF } & & & 3gp & mkv & Mp4 & Mp4 & webm \\
\hline & \multirow{3}{*}{ VIDEO } & Troughput & 0.463 & 0.394 & 0.527 & 0.697 & 0.474 \\
\hline & & Delay & 0,023 & 0,011 & 0,012 & 0,009 & 0,018 \\
\hline & & Paket loss & $0,0 \%$ & $56,4 \%$ & $41,3 \%$ & $38,2 \%$ & 17,9 \\
\hline & \multirow{4}{*}{ AUDIO } & & Mp2 & Mp3 & Mp4 & wave & wma \\
\hline & & Troughput & 0,149 & 0,149 & 0,149 & 0,149 & 0,149 \\
\hline & & Delay & 0,026 & 0,026 & 0,026 & 0,026 & 0,026 \\
\hline & & Paket loss & $0,00 \%$ & $0,00 \%$ & $0,00 \%$ & $0,00 \%$ & $0,00 \%$ \\
\hline \multirow{6}{*}{ RIP } & \multirow{4}{*}{ VIDEO } & & $3 g p$ & mkv & Mp4 & Mp4 & webm \\
\hline & & Troughput & 0,445 & 0,618 & 0,706 & 0,669 & 0,508 \\
\hline & & Delay & 0,024 & 0,014 & 0,009 & 0,012 & 0,020 \\
\hline & & Paket loss & $0,00 \%$ & $18,5 \%$ & $36,9 \%$ & $23,7 \%$ & $4,7 \%$ \\
\hline & & & Mp2 & Mp3 & Mp4 & Wave & wma \\
\hline & & Troughput & 0,149 & 0,150 & 0,148 & 0,149 & 0,149 \\
\hline
\end{tabular}




\begin{tabular}{|l|l|l|l|l|l|l|l|}
\hline & \multirow{2}{*}{ AUDIO } & Delay & 0,026 & 0,026 & 0,026 & 0,026 & 0,026 \\
\cline { 3 - 8 } & & Paket loss & $0,00 \%$ & $0,00 \%$ & $0,00 \%$ & $0,00 \%$ & $0,00 \%$ \\
\hline
\end{tabular}

Berdasarkan dari pengujian terhadap lima buah masing-masing data audio dan video pada tabel 1 disimpulkan bahwa untuk mencari nilai troughput, delay dan paket loss dapat dihitung sebagai berikut :

$$
\begin{aligned}
& \text { Troughput } \quad=\frac{\text { jumlah data yang dikirim }}{\text { waktu pengiriman data }} \\
& \text { Packet Loss }
\end{aligned}
$$

Rata-rata Delay $=$ Total delay $/$ Total paket yang diterima

\section{KESIMPULAN}

Kesimpulan yang dihasilkan pada penelitian ini adalah sebagai berikut :

1. Nilai $Q o S$ untuk routing OSPF, EIGRP dan RIP memenuhi standar ITU-G 11, dengan nilai paling kecil didapat pada routing OSPF dan nilai hasil pengujian ratarata memiliki kualitas yang baik.

2. Jumlah troughput tidak mengalami selisih yang begitu banyak, nilai troughput pada routing OSPF mendapakan nilai lebih kecil dari routing EIGRP dan RIP.

3. Pengujian streaming audio dari routing OSPF, EIGRP dan RIP mendapatkan nilai troughput, delay dan paket loss yang sama.

4. Protookol OSPF, EIGRP dan RIP tebukti mempunyai performansi yang baik untuk pemutaran audio dan video berbentuk streaming dan sudah mencapai standar internasional yang ditetap didalam pengukuran QoS yang ditentukan.

5. Protokol OSPF lebih baik dari protokol routing EIGRP dan RIP.

\section{SARAN}

Penelitian yang dilakukan ini tidak lepas dari kelemahan dan kekurangan. Berdasarkan hasil pengujian dan pengukuran didapat saran-saran sebagai berikut :

1. Pengujian hanya dilakukan menggunakan satu klient, berharap dapat dikembangkan menjadi beberapa klient dan bisa broadcas ke banyak klient .

2. Pengujian dilakukan masih menggunakan berbasis lan, diharapkan pengujian selanjutnya menggunakan studi kasus dan menggunakan jaringan wifi.

3. Pengujian hanya menggunakan laptop sebagai server, diharapkan dikembangkan menggunakan linux sebagai server.

\section{DAFTAR PUSTAKA}

[1] W. Stallings, "Komunikasi Data dan Komputer: Dasar-Dasar Komunikasi Data," Salemba Teknika, Jakarta, 2001.

[2] T. Lammle, CCNA Routing and Switching Study Guide: Exams 100-101, 200-101, and 200-120: John Wiley \& Sons, 2013. 
[3] D. Abdullah, "JARINGAN KOMPUTER. DATA LINK, NETWORK \& ISSUE," ed: Unimal Press, 2015.

[4] A. Siswanto, "Evaluasi Kinerja Wireless 802.11N untuk E Learning," INFORMATION TECHNOLOGY JOURNAL RESEARCH AND DEVELOPMENT, pp. 13-25\%V 1, 201702-08 2017.

[5] L. D. Maryati, R. Primananda, and M. H. H. lchsan, "Analisis Kinerja Protokol Routing OSPF dan EIGRP Untuk Aplikasi VoIP Pada Topologi Jaringan Mesh " Jurnal Pengembangan Teknologi Informasi dan Ilmu Komputer vol. Vol. 1, No. 9, pp. 960-970 1 June 20172017.

[6] P. Utomo and B. E. Purnama, "Pengembangan Jaringan Komputer Universitas Surakarta Berdasarkan Perbandingan Protokol Routing Information Protokol (RIP) Dan Protokol Open Shortest Path First (OSPF)," IJNS-Indonesian Journal on Networking and Security, vol. 1, 2012.

[7] I. Amani, "Perancangan Topologi Jaringan Dengan Menggunakan Protokol Routing EIGRP " Bachelor, Teknik Telekomunikasi, Telkom Universiti, Telkom University, 2010.

[8] H. A. Musril, "Analisis Unjuk Kerja RIPv2 dan EIGRP dalam Dynamic Routing Protocol," Jurnal Elektro dan Telekomunikasi Terapan, vol. 2, 2016.

[9] J. T. Moy, OSPF: anatomy of an Internet routing protocol: Addison-Wesley Professional, 1998.

[10] R. Guerin, S. Kamat, A. Orda, T. Przygienda, and D. Williams, "QoS routing mechanisms and OSPF extensions," draft-guerin-qos-routing-ospf-03. txt, 1999.

[11] R. Albrightson, J. Garcia-Luna-Aceves, and J. Boyle, "EIGRP--A fast routing protocol based on distance vectors," 1994.

[12] J. Saputro, Praktikum CCNA di Komputer Sendiri Menggunakan GNS3: MediaKita, 2010.

[13] A. Siswanto and A. Tedyyana, "Manajemen Bandwidth dan Monitoring Akses Data," in Seminar Nasional Teknologi Informasi dan Komunikasi, Medan, 2014, pp. 24-28.

[14] Y. Arta, E. A. Kadir, and D. Suryani, "KNOPPIX: Parallel computer design and results comparison speed analysis used AMDAHL theory," in Information and Communication Technology (ICoICT), 2016 4th International Conference on, 2016, pp. 1-5. 